\title{
Differential Expression of Glycosylphosphatidylinositol-anchored Proteins in a Murine T Cell Hybridoma Mutant Producing Limiting Amounts of the Glycolipid Core Implications for Paroxysmal Nocturnal Hemoglobinuria
}

\author{
Lawrence J. Thomas, Masaharu Urakaze, Rita DeGasperi, ${ }^{\ddagger}$ Tetsu Kamitani, Eiji Sugiyama, \\ Hui-Ming Chang, * Christopher D. Warren, and Edward T. H. Yeh \\ Arthritis Unit, Department of Medicine; ${ }^{*}$ Pain Control Unit, Department of Anesthesia; and ${ }^{\ddagger}$ Department of Biological Chemistry \\ and Molecular Pharmacology, Harvard Medical School, Massachusetts General Hospital, Boston, Massachusetts 02114
}

\begin{abstract}
A $\mathbf{T}$ cell hybridoma mutant, which expressed a markedly reduced level of glycosylphosphatidylinositol (GPI)-anchored proteins on the cell surface, was characterized. The surface expression level of Thy-1 was $\sim 17 \%$ of the wild-type level, whereas the surface expression of $\mathrm{Ly}-6 \mathrm{~A}$ was $\sim 2.4 \%$ of the wild-type level. We show here that these cells synthesized limiting amounts of the GPI core and that the underlying defect in these cells was an inability to synthesize dolichyl phosphate mannose (Dol-P-Man) at the normal level. The defect in Ly-6A expression could be partially corrected by tunicamycin, which blocked the biosynthesis of $\mathrm{N}$-linked oligosaccharide precursors and shunted Dol-P-Man to the GPI pathway. Full restoration of Thy-1 and Ly-6A expression, however, required the stable transfection of a yeast Dol-P-Man synthase gene into the mutants. These results revealed that when the GPI core is limiting, there is a differential transfer of the available GPI core to proteins that contain GPI-anchor attachment sequences. Our findings also have implications for the elucidation of the defects in paroxysmal nocturnal hemoglobinuria. (J. Clin. Invest. 1992. 89:1172-1177.) Key words: glycosylphosphatidylinositol anchor • paroxysmal nocturnal hemoglobinuria
\end{abstract}

\section{Introduction}

As an alternative to the use of a transmembrane region, proteins may be attached to membranes via a glycosylphosphatidylinositol (GPI) ${ }^{1}$ anchor. A biosynthetic pathway for the GPI anchor has been characterized in mammalian cells, and it

Dr. DeGasperi's present address is Department of Neurology, New York University Medical Center, 550 First Avenue, New York, NY 10016.

Address reprint requests to Dr. Edward T. H. Yeh, Arthritis Unit, Department of Medicine, Massachusetts General Hospital, Boston, MA 02114.

Received for publication 21 October 1991 and in revised form 3 December 1991.

1. Abbreviations used in this paper: Dol-P-Man, dolichyl phosphate mannose; FITC-GAMG, fluorescein isothiocyanate-goat anti-mouse IgG; GlcN-PI, glucosaminylphosphatidylinositol; GlcNAc-PI, $N$-acetylglucosaminylphosphatidylinositol; GPI, glycosylphosphatidylinositol; PI, phosphatidylinositol; PNH, paroxysmal nocturnal hemoglobinuria.

\section{J. Clin. Invest.}

(C) The American Society for Clinical Investigation, Inc.

0021-9738/92/04/1172/06 \$2.00

Volume 89, April 1992, 1172-1177 shares some similarity with the trypanosomal pathway (1-8). The first two anchor precursors found are $N$-acetylglucosaminyl-phosphatidylinositol (GlcNAc-PI) and glucosaminylphosphatidylinositol (GlcN-PI) which are synthesized by the transfer of GlcNAc from UDP-GlcNAc to phosphatidylinositol (PI) and subsequent $N$-deacetylation (2-4). Subsequently, GlcN-PI is fatty-acylated in the inositol ring and mannose residues are added from dolichyl phosphate mannose (Dol-PMan) (1, 2). Finally, one or more residues of ethanolamine phosphate are added to the mannosylated GPI precursors (1, 2). The transfer of the preformed GPI core to the carboxy termini of proteins has not been directly demonstrated in the mammalian system. It has been postulated that the transfer requires a novel transamidase, which cleaves the carboxy termini of proteins that have appropriate cleavage and attachment signals and transfers the preformed cores to them (9-15). Although a consensus sequence has not been defined, a carboxy-terminal hydrophobic domain and small amino acids at the cleavage sites are the general requirements $(14,15)$.

We have defined defects in GPI anchor biosynthesis in a large panel of $T$ cell mutants $(1,2)$. These mutants cannot express GPI-anchored proteins on the cell surface because their incompletely formed GPI-anchor precursors cannot be transferred to proteins (16-19). In this paper, we characterize a T cell mutant that expressed reduced levels of GPI-anchored proteins on the cell surface. Interestingly, two proteins studied, Thy-1 and Ly-6A, are not reduced to the same extent. The surface expression level of Thy-1 was $17 \%$ of the wild-type level, whereas the surface expression of Ly-6A was $2.4 \%$ of the wild-type level. The biosynthetic defect in this mutant was shown to be a deficient production of Dol-P-Man, which is the donor of mannose residues in the biosynthesis of the GPI anchor $(1,20)$. Predictably, the synthesis of the complete GPI core in this mutant was seen to be severely deficient, which presumably led to the reduced surface expression of GPI-anchored proteins. We were able to rescue the biosynthetic defect with a yeast Dol-P-Man synthase gene (1). With an increased level of Dol-P-Man biosynthesis, the surface expression of Ly$6 \mathrm{~A}$ and Thy-1 was returned to the wild-type level. This observation implies that when the GPI core was limiting, as in the case of the mutant described here, there was a preferential transfer of the available GPI core to certain proteins that contain GPI-anchor attachment sequences.

Defects in either GPI anchor biosynthesis or attachment have been implicated in the pathogenesis of paroxysmal nocturnal hemoglobinuria (PNH), an acquired hematopoietic stem cell disorder (21-23). A large number of GPI-anchored proteins have been found to be either absent or deficient on the surface of hematopoietic cells (24-28). This can be accounted 
for by defects, either partial or complete, in the biosynthesis of the GPI anchor. Recently, it has been shown in several PNH patients that there is a discordance in the expression of GPI-anchored proteins in different cell types $(29,30)$. The biosynthetic defects in these PNH patients have not been defined, however. Our results, therefore, provide a theoretical explanation for the differential expression of GPI-anchored proteins in granulocytes and erythrocytes derived from PNH patients.

\section{Methods}

Reagents and antibodies. The anti-Ly-6A antibody (3E7.1) has been previously described (31). The following mAbs were kindly provided by the laboratories that developed them: anti-Thy-1 (M5/49) (32), and anti-CD3 (145-2C11) (33). Antibodies were used as tissue culture supernatants, containing $10 \%$ FCS. The plasmid containing the gene encoding Dol-P-Man synthase was the gift of Drs. P. J. Beck and J. Sambrook (University of Texas Southwestern Medical Center, Dallas, Texas) (34).

Cell culture. T cell hybridomas YH16.33 and M38/20, have been described previously $(1,35)$. They were maintained in RPMI 1640 medium, which had been supplemented with $10 \%$ FCS and penicillin, streptomycin, and fungizone.

Glycolipid labeling and TLC separation. GPI anchor precursors were identified as described previously $(1,2) .2 \times 10^{7}$ cells were labeled for $45 \mathrm{~min}$ with $\left[{ }^{3} \mathrm{H}\right]$ mannose $(20 \mu \mathrm{Ci} / \mathrm{ml})$ in low glucose $(0.1 \mathrm{~g} /$ liter $)$ RPMI in the presence of $10 \mu \mathrm{g} / \mathrm{ml}$ of tunicamycin. The lipids were extracted with $\mathrm{CHCl}_{3} / \mathrm{CH}_{3} \mathrm{OH} / \mathrm{H}_{2} \mathrm{O}$ (10:10:3). The lipid extract was dried, dissolved in water-saturated butanol and partitioned with $\mathrm{H}_{2} \mathrm{O}$. The butanol phase was dried and blotted on a silica gel 60 plate (EM Science, Gibbstown, NJ). TLC plates were developed in $\mathrm{CHCl}_{3} /$ $\mathrm{CH}_{3} \mathrm{OH} / \mathrm{H}_{2} \mathrm{O}$ (10:10:3), scanned, and autoradiographed.

Transfection. $2 \times 10^{7}$ mutant cells (M43/8) were washed with PBS twice and resuspended in $1.6 \mathrm{ml}$ of ice-cold PBS. $80 \mu \mathrm{g} / 400 \mu \mathrm{l}$ of undigested plasmid which contained the Dol-P-Man synthase gene was added to the cells. The plasmid was stably transfected into the cells by electroporation $(175 \mathrm{~V}, 1000 \mu \mathrm{F})$, using a Cell-Zap IIb electroporator (Owl Scientific, Cambridge, MA) and a Cell-Porator cuvette holder (Gibco Bethesda Research Laboratories, Gaithersburg, MD). After 48 hours, the cells were resuspended in RPMI 1640 medium containing $1.5 \mathrm{mg} / \mathrm{ml} \mathrm{G418} \mathrm{(G418} \mathrm{sulfate,} \mathrm{Geneticin;} \mathrm{GIBCO} \mathrm{BRL)} \mathrm{and} \mathrm{ali-}$ quoted into microtiter plates. Clones that survived the antibiotic selection were then switched over to regular culture media without G418 and characterized.

Immunofluoresence staining. Indirect immunofluorescent staining was performed as described (35) using an mAb-containing tissue culture supernatant followed by fluorescein isothiocyanate goat antimouse IgG (FITC-GAMG) (Caltag Laboratories, San Francisco, CA), under nonlimiting conditions. Fluorescence was quantitated on a FACScan fluorescence-activated cytometer (Becton Dickinson Co., Mountain View, CA). As a negative control, cells were incubated with fresh tissue culture media containing $10 \%$ FCS, instead of the specific first antibody, before incubation with FITC-GAMG. For PI-PLC treatment, cells $\left(5 \times 10^{6}\right)$ were incubated for $60 \mathrm{~min}$ at $37^{\circ} \mathrm{C}$ in RPMI 1640 with BSA $(2 \mathrm{mg} / \mathrm{ml})$ and $0.1 \% \mathrm{NaN}_{3}$. PI-PLC $(0.4 \mathrm{U} / \mathrm{ml})$ was used for the treatment group. Staining and analysis were performed as described above. For tunicamycin treatment, cells were incubated in culture media supplemented with $0.5 \mathrm{mg} / \mathrm{ml}$ tunicamycin for $18 \mathrm{~h}$, washed, and stained as described. For the calculation of the percent reduction of surface expression, the following formula was used: [(fluoresence of M43/8 after specific antibody staining) - (fluoresence of M43/8 after nonspecific antibody staining)]/[(fluoresence of YH16.33 after specific antibody staining) - (fluoresence of YH16.33 after nonspecific antibody staining)].

Dol-P-Man synthase assay. Cells were lysed in $0.1 \mathrm{mM} N$-tosyl-Llysine chloromethyl ketone (TLCK), $1 \mathrm{mg} / \mathrm{ml}$ leupeptin in water, diluted to $10^{9} \mathrm{cells} / \mathrm{ml}$ with an equal amount of $0.1 \mathrm{M}$ Hepes (pH 7.4) with $50 \mathrm{mM} \mathrm{KCl}, 10 \mathrm{mM} \mathrm{MgCl} 2,0.1 \mathrm{mM}$ TLCK, $1 \mu \mathrm{g} / \mathrm{ml}$ leupeptin, and $20 \%$ glycerol, and frozen at $-70^{\circ} \mathrm{C}$. Defrosted lysates were washed twice with $10 \mathrm{ml}$ of $50 \mathrm{mM}$ Hepes (pH 7.4), $25 \mathrm{mM} \mathrm{KCl}, 5 \mathrm{mM} \mathrm{MnCl}$, $0.1 \mathrm{mM} \mathrm{TLCK}$, and $1 \mathrm{mg} / \mathrm{ml}$ leupeptin (spun at $6,000 \mathrm{~g}$ for $10 \mathrm{~min}$ ). The pellet was resuspended in the above buffer. The samples (containing membranes from $6 \times 10^{6}$ cells) were assayed in a final volume of $200 \mu \mathrm{l}$ of $50 \mathrm{mM}$ Hepes (pH 7.4) with $25 \mathrm{mM} \mathrm{KCl}, 5 \mathrm{mM} \mathrm{MnCl}_{2}, 5$ $\mathrm{mM} \mathrm{MgCl} 2,0.1 \mathrm{mM}$ TLCK, $1 \mathrm{mg} / \mathrm{ml}$ leupeptin, $0.1 \mathrm{mM}$ DTT, $0.0025 \% \mathrm{NP}-40,100 \mu \mathrm{g} / \mathrm{ml}$ phosphatidylethanolamine, $2.6 \mu \mathrm{g} / \mathrm{ml}$ dolichyl phosphate, and $200,000 \mathrm{cpm}$ of $\left[{ }^{3} \mathrm{H}\right] \mathrm{GDP}-$ mannose. After incubation at $37^{\circ} \mathrm{C}$ for the appropriate length of time, the reaction was stopped by the addition of $1 \mathrm{ml}$ of $2: 1 \mathrm{CHCl}_{3} / \mathrm{CH}_{3} \mathrm{OH}$. After centrifuging, the organic phase was retained and washed three times with $\mathrm{CHCl}_{3} / \mathrm{CH}_{3} \mathrm{OH} / \mathrm{H}_{2} \mathrm{O}$ (3:48:47), and counted. The samples were also separated by TLC in $\mathrm{CHCl}_{3} / \mathrm{CH}_{3} \mathrm{OH} / \mathrm{H}_{2} \mathrm{O}, 60: 35: 8$. Scanning and autoradiography revealed that $\sim 95 \%$ of the counts was consistently contained in Dol-P-Man. The area of the TLC corresponding to Dol-PMan, determined by overlaying autoradiographs, was scraped off the support and the incorporated radioactivity was determined by liquid scintillation counting. The protein content of the cell lysates was assayed with Coomassie Plus Protein Assay (Pierce Chemical Co., Rockford, IL).

\section{Results}

A T cell hybridoma, specific for chicken ovalbumin, YH16.33, was mutagenized and mutant clones were selected for resistance to killing by anti-Ly-6A antibody and complement (35). Clones were examined by FACS analysis for the surface expression of Ly-6A and Thy-1. One clone, M43/8, expressed two GPI-anchored proteins at levels significantly below those of wild-type cells (Fig. 1, $A-D$ ). Levels of Ly-6A were, on the

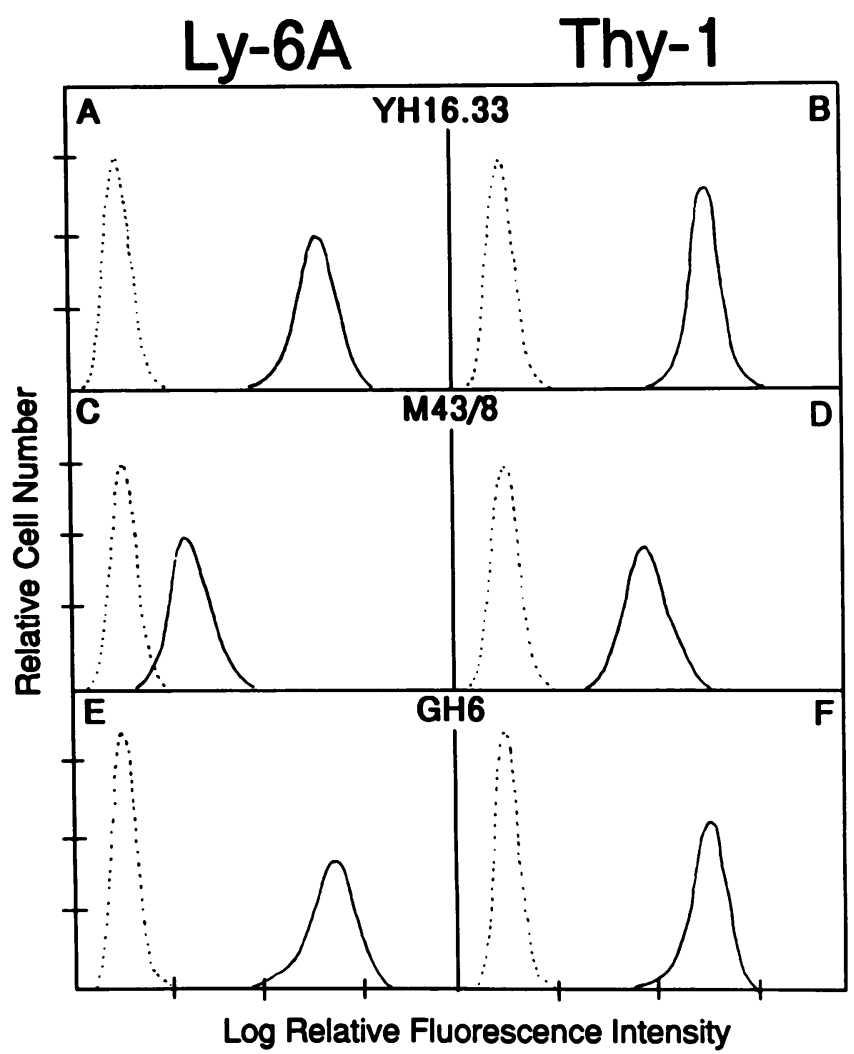

Figure 1. FACS staining of wild type, YH16.33, $(A$ and $B)$, mutant, M43/8, $(C$ and $D)$, and transfectant, GH6, $(E$ and $F)$ cells for Ly-6A $(A, C$, and $E)$ and Thy-1 $(B, D$, and $F)$. Indicated are the negative control $(\cdots \cdots)$, and specific first-step antibody followed by FITC-GAMG (-). 
average, $\sim 2.4 \%$ of normal, while levels of Thy-1 were, on the average, $\sim 17 \%$ of normal. Similar staining patterns were also observed using different monoclonal antibodies against Ly-6A or Thy-1 (data not shown). The lower level of expression of two GPI-anchored proteins could have been due to a decrease in the production or in the transfer of the preformed GPI core to proteins, or due to a nonspecific defect in protein synthesis. These possibilities could be distinguished by metabolic labeling of the preformed GPI precursors. Thus, the same number of wild-type and mutant cells were labeled with $\left[{ }^{3} \mathrm{H}\right]$ mannose in the presence of tunicamycin. Labeled glycolipids were extracted, chromatographed, and autoradiographed as described previously $(1,2)$. Fig. $2 A$ shows a representative TLC autoradiograph of $\left[{ }^{3} \mathrm{H}\right]$ mannose-labeled GPI intermediates in the wild type and mutant cells. As shown, the wild type cells form all of the GPI precursors previously defined (2). The mutant cell, however, did not synthesize detectable amounts of mannose-containing GPI precursors (other than $\mathrm{M}_{1}$ ) or the complete GPI core $(C)$. In another experiment with longer exposure one could detect a faint spot in the core area (Fig. 2 B). To quantitate the difference, the TLC plates were scanned with a linear radioisotope scanner and the area corresponding to the core in both the wild type and the mutant cells determined. The mutant contained $<1 \%$ radioactivity in the core area as

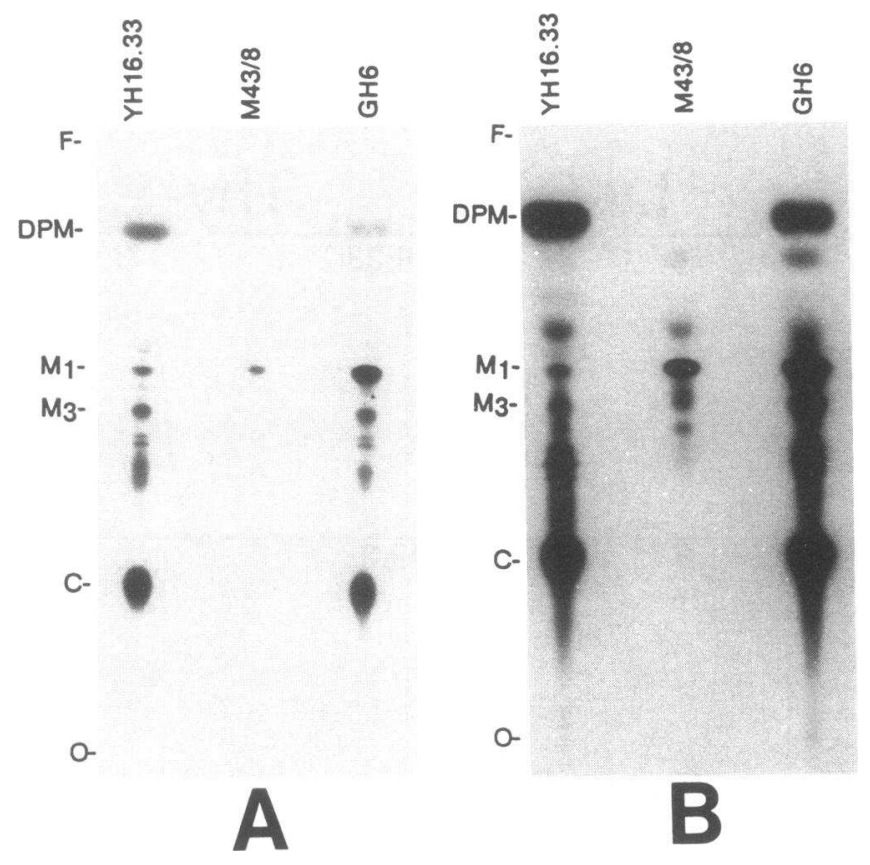

Figure 2. Mannose-containing glycolipids in $\mathrm{YH} 16.33$, M43/8, and GH6 cells. Plates from two separate experiments were sprayed with fluor and autoradiographed for $3 \mathrm{~d}(A)$ or $1 \mathrm{mo}(B)$. It should be noted that $5 \times 10^{5}$ cell equivalents of glycolipid extracts were loaded to each lane. There are at least two glycolipids migrating between $M_{3}$ and $C$. Recent results show that these glycolipids can be labeled with $\left[{ }^{3} \mathrm{H}\right]$ ethanolamine. We are in the process of further characterizing these glycolipids, which may contain a variable number of ethnolamine phosphate residues and/or other modifications. The pertinent finding for this report is that they are all markedly reduced in the mutant and restored in the transfectant. DPM, dolichyl mannosyl phosphate; $C$, GPI precursor that contains ethanolamine phosphate; $F$, front; $M_{1,3}$, GPI precursors containing one or three mannose residues; $O$, origin. These precursors have been described in detail previously $(1,2)$. compared to the wild type. This result is reproducible in five separate experiments. Thus, the reduced surface expression of GPI-anchored proteins in the mutant was due to deficient anchor biosynthesis. Since the GPI core was formed at such a low level in the mutant, it was important to determine whether the surface-expressed Thy-1 and Ly-6A were indeed anchored by the GPI tail, and not by alternative means. Fig. 3 shows that both Ly-6A and Thy-1 were sensitive to PI-PLC treatment whereas the non-GPI-anchored CD3 $\epsilon$ was not. These results thus established the direct correlation between low GPI core formation and reduced surface expression of GPI-anchored proteins.

Fig. $2 A$ also reveals the cause of the deficient GPI anchor formation. As shown, Dol-P-Man, the mannose donor for the GPI anchor, was not detectable in the mutant. This was independently confirmed by assaying for Dol-P-Man synthase activity. In Fig. 4 it is shown that the Dol-P-Man synthase activity was at a baseline level, similar to another mutant (M38/20) which had been shown to produce no Dol-P-Man at all. Our inability to detect a low level of Dol-P-Man synthase activity in M43/8 does not mean that M43/8 is completely deficient in this enzyme since $(a)$ a trace amount of GPI core was still synthesized (Fig. $2 \mathrm{~B}$ ), and (b) the Dol-P-Man assay assesses the steady state level of Dol-P-Man, since enzymes that use Dol-PMan are present and presumably active. This point was clearly demonstrated by incubating the mutant with tunicamycin, which blocked the transfer of mannose residues from Dol-PMan to $N$-linked oligosaccharide precursors and shunted Dol-

\section{YH16.33 M43/8}

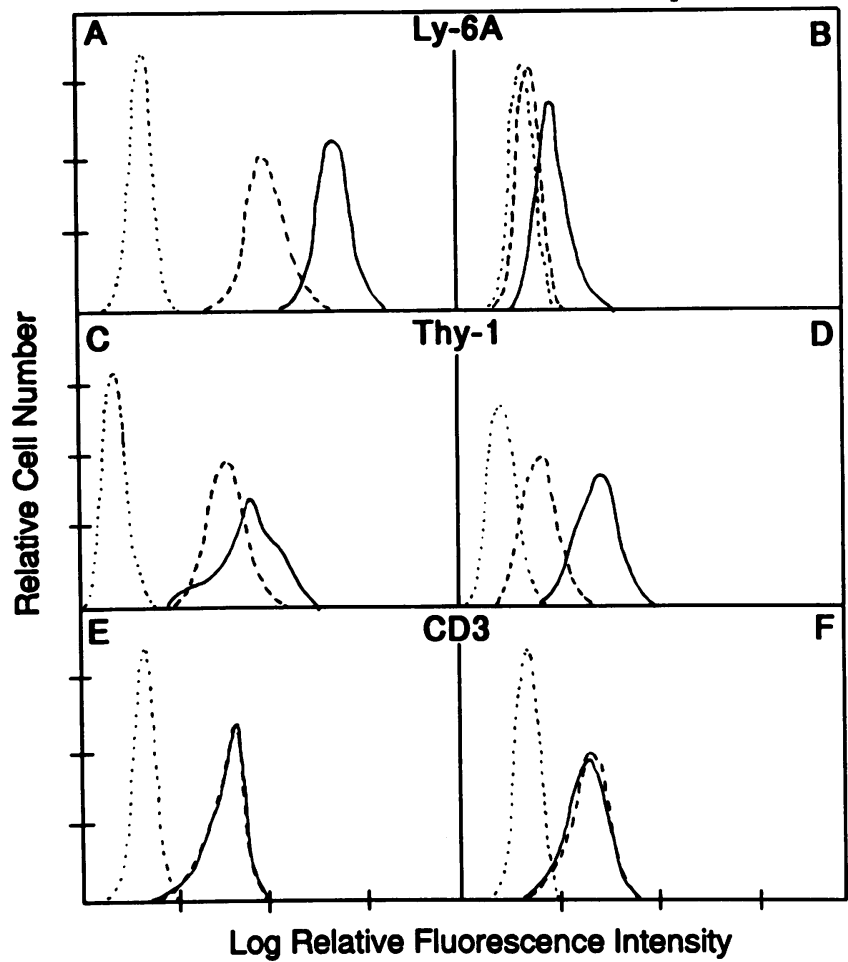

Figure 3. PI-PLC sensitivity of membrane proteins. YH16.33 $(A, C$, and $E)$ and $\mathrm{M} 43 / 8(B, D$, and $F)$ cells were treated with PI-PLC and stained with antibodies to Ly-6A $(A$ and $B)$, Thy-1 ( $C$ and $D)$, or CD3 $(E$ and $F)$. Indicated are the negative control $(\cdots \cdots)$, mock digestion (-), and PI-PLC digestion (---.---). 


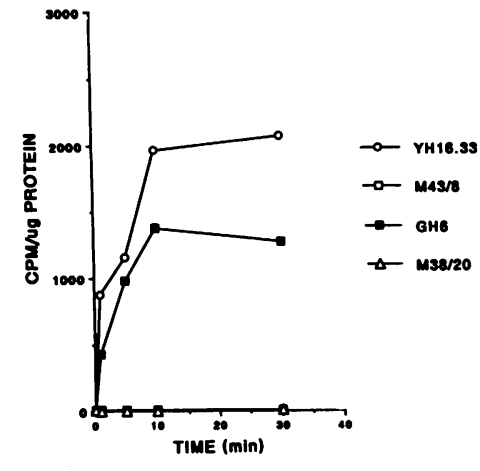

Figure 4. Production of Dol-P-Man in wild-type (YH16.33), mutants (M43/ $8, M 38 / 20)$, and transfectant (GH6) cells. Dol-PMan synthase activity of cell lysates were assayed and organic-soluble compounds were separated by TLC. The areas of the TLC corresponding to Dol-PMan were scraped off the support and incorporated radioactivity was deter-

mined. Incorporated counts were corrected for the protein content of the assayed lysate. Since enzymes that use Dol-P-Man were present and active, this assay represents a steady-state concentration of DolP-Man.

P-Man to the GPI pathway (36) (Fig. 5). As shown, in M43/8 cells cultured with tunicamycin for $18 \mathrm{~h}$, the surface expression of Ly-6A had returned to almost wild-type level. However, the surface expression of Thy-1 remained unchanged. This was most likely due to the deleterious effect of tunicamycin on $N$-linked glycosylation, because Thy-1 contained three $N$ linked glycosylation sites whereas Ly-6A had none (37-39). This conclusion was supported by the observation that in wild type cells incubated with tunicamycin for $18 \mathrm{~h}$, the surface

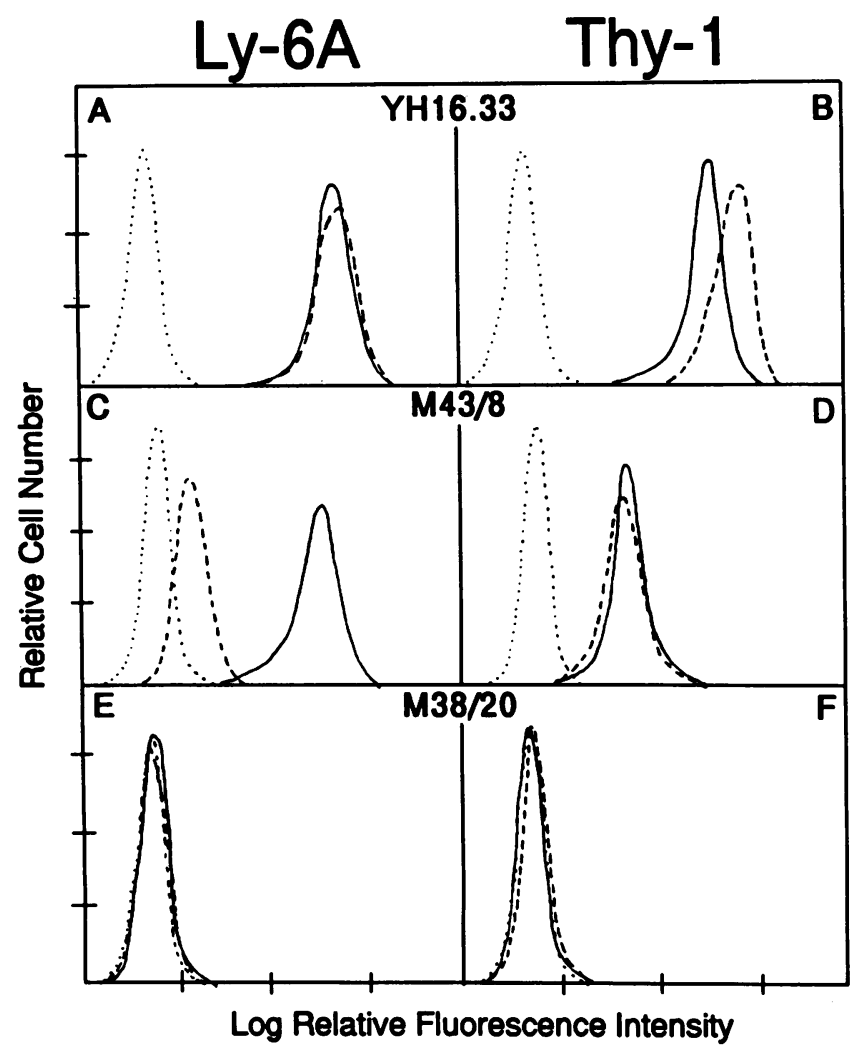

Figure 5. The effect of tunicamycin on Ly-6A or Thy-1 expression in the wild type, YH16.33, $(A$ and $B)$ or mutants, M43/8 ( $C$ and $D)$ or $\mathrm{M} 38 / 20(E$ and $F)$. Indicated are the negative control $(\cdots \cdots)$, sample treated with tunicamycin $(-)$, and without tunicamycin (-------). expression of Thy-1, but not Ly-6A, was decreased (Fig. 5, $A$ and $B$ ). Restoration of Ly-6A expression in M43/8 demonstrated the presence of endogenous Dol-P-Man because M38/ 20 , which is completely deficient in Dol-P-Man production, could not be corrected by tunicamycin treatment (Fig. 5, E and $F$ ).

Since, tunicamycin did not restore both Thy-1 and Ly-6A expression in the mutant to the wild type level, due to the inherent toxicity of tunicamycin on $\mathrm{N}$-glycosylation, which probably interfered with normal folding and/or transport of Thy-1, we attempted to correct the defect by alternative means. We have shown previously that the yeast Dol-P-Man synthase gene can restore GPI anchor synthesis in mutants which cannot synthesize any Dol-P-Man (1). This approach was used to correct the defect in M43/8. Thus, M43/8 was transfected with an expression vector that contained the Dol-P-Man synthase and G418 resistance gene, as previously described (1). 38 subclones survived the G418 selection. 37 of them had surface expression of Thy-1 and Ly-6A corrected to the wild-type levels. It should be noted that GH6 was maintained in culture media in the absence of G418 for several months. Thus, the changes described below cannot be due to metabolic correction with G418. Dol-P-Man mutants transfected with the plasmid containing the Dol-P-Man synthase gene in a reverse orientation did not correct the deficient phenotype (Thomas, L., and E. Yeh, unpublished data). A representative clone, GH6, is shown in Fig. 1. As shown, GH6 expressed Thy-1 and Ly-6A at levels slightly higher than that of the wild type, indicating that the ability to produce GPI anchors had been restored. TLC analysis of GPI biosynthetic intermediates showed that the complete GPI core, as well as Dol-P-Man was produced in GH6 (Fig. 2). The ability to produce Dol-P-Man was also assayed (Fig. 4). In this assay, the maximal level of Dol-P-Man in GH6 was $\sim 60 \%$ of the wild type's.

\section{Discussion}

In this paper we have described a $T$ cell hybridoma mutant which can only synthesize below-normal levels of Dol-P-Man. As a consequence, the mutant synthesized a greatly reduced amount of the complete GPI core, which led to a reduced expression of GPI-anchored proteins on the cell surface. Interestingly, Ly-6A expression was more significantly affected than Thy- 1 . We demonstrated that the differential expression of GPI-anchored proteins was due to limited availability of preformed GPI core because this defect could be rescued metabolically or genetically.

The rules that govern the attachment of the GPI anchor to proteins are not entirely known. The enzyme that cleaves the carboxy terminus presumably has to recognize a cleavage signal in proteins destined to be GPI anchored, and transfer a preformed GPI core to the attachment site. If the GPI core is produced in excess, the surface expression of GPI-anchored proteins would probably be dependent on the amounts of the proteins synthesized. However, when the core is limiting, there may be a competition for the available core. The factors that determine which proteins get preferential transfer are probably contained within the GPI cleavage and attachment sequence. In M43/8 the differential expression of Ly-6A versus Thy- 1 is most likely due to differences in these factors. It should be noted that the basic biosynthetic defect in M43/8 is deficient 
Dol-P-Man synthesis, which, predictably, affects $N$-linked glycosylation (Thomas, L., and R. DeGasperi, data not shown). Since Thy- 1 is $N$-glycosylated, but Ly-6A is not (37-39), one would expect Thy-1 expression in M43/8 to be more adversely affected than Ly-6A. The observation to the contrary, i.e., that the surface expression of Ly-6A was more diminished than that of Thy-1, suggested that deficient GPI core formation is the primary cause of the differential expression. In the future, when more GPI-anchored protein sequences have been sequenced, an optimal sequence may be deduced. This would be beneficial in the construction of GPI-anchored recombinant proteins, particularly when over-expression is desired.

Significant insight into the biosynthesis of the GPI anchor has been gained by studying a panel of well-defined mutants (1, 2). This is the first time that a partial defect of Dol-P-Man production has been defined and genetically corrected. The methods that we have described in this and previous reports should provide the necessary tools to define the defects in GPI anchor formation in PNH patients $(1,2)$. Two main lessons are learned from our analysis. The first is that it is often difficult to state unequivocally that a defect in GPI anchor biosynthesis is absolute. In our initial analysis of M43/8, we thought that the complete GPI anchor precursor was not formed at all. With repeated experiments, we then established that the core precursor is formed at $\sim 1 \%$ of the wild-type level. Thus, when metabolic labeling is used in the analysis of PNH defects, care must be exercised to ascertain whether or not an apparently complete defect could be due to the sensitivity of the detection system. The second lesson is that if the GPI core is limiting, then differential expression of GPI-anchored proteins might result. This may well explain the diminished expression of CD16 in PNH granulocytes that are CD55 and CD59 negative, and diminished expression of LFA-3 and acetylcholinesterase in PNH erythrocytes which are DAF-negative $(29,30)$.

\section{Acknowledgments}

This work was supported by National Institutes of Health Grants AR03564, HL-45851 (E. T. H. Yeh), National Institute of Arthritis and Musculoskeletal and Skin Disease Training Grant T32AR07258-15 (L. J. Thomas), DK-40930, SO7-RR05486-28 (C. D. Warren).

\section{References}

1. DeGasperi, R., L. J. Thomas, E. Sugiyama, H. M. Chang, P. Beck, P. Orlean, C. Albright, G. Waneck, J. Sambrook, C. D. Warren, and E. T. H. Yeh. 1990. Correction of a defect in mammalian GPI anchor biosynthesis by a transfected yeast gene. Science (Wash. DC). 250:988-991.

2. Sugiyama, E., R. DeGasperi, M. Urakaze, H. M. Chang, L. J. Thomas, R. Hyman, C. D. Warren, and E. T. H. Yeh. 1991. Identification of defects in glycosylphosphatidylinositol anchor biosynthesis in the Thy-1 expression mutants. J. Biol. Chem. 266:12119-12122.

3. Hirose, S., L. Ravi, S. V. Hazra, and M. E. Medof. 1991. Assembly and deacetylation of $\mathrm{N}$-acetylglucosaminylplasmanyinositol in normal and affected paroxysmal nocturnal hemoglobinuria cells. Proc. Natl. Acad. Sci. USA. 88:3762-3766.

4. Stevens, V., and C. R. H. Raetz. 1991. Defective glycosylphosphatidylinositol biosynthesis in extracts of three Thy-1 negative lymphoma cell mutants. $J$. Biol. Chem. 266:10039-10042.

5. Doering, T. L., W. J. Masterson, G. W. Hart, and P. T. Englund. 1990. Biosynthesis of glycosylphosphatidylinositol membrane anchors. J. Biol. Chem. 265:611-614.

6. Masterson, W. J., T. L. Doering, G. W. Hart, and P. T. Englund. 1989. A novel pathway for glycan assembly: biosynthesis of the glycosyl-phosphatidylinositol anchor of the trypanosome variant surface glycoprotein. Cell. 56:793-800.
7. Mayor, S., A. K. Menon, and G. A. Cross. 1990. Glycolipid precursors for the membrane anchor of Trypanosoma brucei variant surface glycoproteins. II. Lipid structures of phosphatidylinositol-specific phospholipase $C$ sensitive and resistant glycolipids. J. Biol. Chem. 265:6174-6181.

8. Mayor, S., A. K. Menon, G. A. Cross, M. A. Ferguson, R. A. Dwek, and T. W. Rademacher. 1990. Glycolipid precursors for the membrane anchor of Trypanosoma brucei variant surface glycoproteins. I. Can structure of the phosphatidylinositol-specific phospholipase $\mathrm{C}$ sensitive and resistant glycolipids. $J$. Biol. Chem. 265:6164-6173.

9. Ferguson, M. A. J., M. Duszenko, G. S. Lamont, P. Overath, and G. A. M. Cross. 1986. Biosynthesis of Trypanosoma brucei variant surface glycoproteins. $J$. Biol. Chem. 261:356-362.

10. Ferguson, M. A. J., and A. F. Williams. 1988. Cell-surface anchoring of proteins via glycosyl-phosphatidylinositol structures. Annu. Rev. Biochem. 57:285-320.

11. Caras, I. W., G. N. Weddell, M. A. Davitz, V. Nussenzweig, and D. W. J. Martin. 1987. Signal for attachment of a phospholipid membrane anchor in decay accelerating factor. Science (Wash. DC). 238:1280-1283.

12. Waneck, G. L., M. E. Stein, and R. A. Flavell. 1988. Conversion of a PI-anchored protein to an integral membrane protein by a single amino acid mutation. Science (Wash. DC). 241:697-700.

13. Berger, J., A. D. Howard, L. Brink, L. Gerber, J. Haubert, B. R. Cullen, and S. Udenfriend. 1988. COOH-terminal requirements for the correct processing of a phosphatidylinositol-glycan anchored membrane protein. J. Biol. Chem. 263:10016-10021.

14. Micanovic, R., K. Kodukula, L. D. Gerber, and S. Udenfriend. 1990. Selectivity at the cleavage/attachment site of phosphatidylinositol-glycan anchored membrane proteins is enzymatically determined. Proc. Natl. Acad. Sci. USA. 87:7939-7943.

15. Moran, P., H. Raab, W. J. Kohr, and I. W. Caras. 1991. Glycophospholipid membrane anchor attachment. Molecular analysis of the attachment site. $J$. Biol. Chem. 266:1250-1257.

16. Conzelmann, A., A. Spiazzi, R. Hyman, and C. Bron. 1986. Anchoring of membrane via phosphatidylinositol is deficient in two classes of Thy-1 negative mutant lymphoma cells. EMBO (Eur. Mol. Biol. Organ.) J. 5:3291-3296.

17. Conzelmann, A., A. Spiazzi, C. Bron, and R. Hyman. 1988. No glycolipid anchors are added to Thy-1 glycoprotein in Thy-1 negative mutant thymoma cells of four different complementation classes. Mol. Cell. Biol. 8:674-678.

18. Fatemi, S. H., and A. M. Tartakoff. 1988. The phenotype of five classes of T lymphoma mutants. J. Biol. Chem. 263:1288-1294.

19. Fatemi, S. H., and A. M. Tartakoff. 1986. Hydrophilic anchor-deficient Thy-1 is secreted by a Class E mutant T lymphoma. Cell. 46:653-657.

20. Menon, A. K., S. Mayor, and R. T. Schwarz. 1990. Biosynthesis of glycosylphosphatidylinositol lipids in Trypanosoma brucei: involvement of mannosylphosphoryldolichol as the mannose donor. EMBO (Eur. Mol. Biol. Organ.) J. 9:4249-4258.

21. Rosse, W. F. 1990. Paroxysmal nocturnal hemoglobinuria and decay-accelerating factor. Annu. Rev. Med. 41:431-436.

22. Parker, C. J. 1990. Paroxysmal nocturnal hemoglobinuria. Clin. Asp. Autoimmun. 5:8-21.

23. Stafford, H. A., M. L. Tykocinski, D. M. Lublin, V. M. Holers, W. F. Rosse, J. P. Atkinson, and E. Medof. 1988. Normal polymorphic variations and transcription of the decay accelerating factor gene in paroxysmal nocturnal hemoglobinuria cells. Proc. Natl. Acad. Sci. USA. 85:880-884.

24. Nicholson-Weller, A., D. B. Spicer, and K. F. Austen. 1985. Deficiency of the complement regulatory protein, "decay accelerating factor," on membranes of granulocytes, monocytes, and platelets in paroxysmal nocturnal hemoglobinuria. N. Engl. J. Med. 312:1091-1097.

25. Brimijoin, S., P. I. Hammond, and R. M. Pettit. 1986. Paroxysmal nocturnal hemoglobinuria: erythrocyte acetylcholinesterase deficit analyzed by immunoassay and fluorescence-activated sorting. Mayo Clin. Proc. 61:522-529.

26. Selvaraj, P., M. L. Dustin, R. Silber, M. G. Low, and T. A. Springer. 1987. Deficiency of lymphocyte function-associated antigen 3 (LFA-3) in paroxysmal nocturnal hemoglobinuria. Functional correlates and evidence for a phosphatidylinositol membrane anchor. J. Exp. Med. 166:1011-1025.

27. Burroughs, S. F., D. V. Devine, G. Browne, and M. E. Kaplan. 1988. The population of paroxysmal nocturnal hemoglobinuria neutrophils deficient in decay-accelerating factor is also deficient in alkaline phosphatase. Blood. 71:10861089.

28. Blass, P., B. Berger, S. Weber, H. H. Peter, and G. M. Hansch. 1988. Paroxysmal nocturnal hemoglobinuria. Enhanced stimulation of platelets by the terminal complement components is related to the lack of C8bp in the membrane. J. Immunol. 140:3045-3051.

29. Edberg, J., J. E. Salmon, M. Whitlow, and R. P. Kimberly. 1991. Preferential expression of human Fc $\gamma$ RIII $_{\text {pmn }}$ (CD16) in paroxysmal nocturnal hemoglobinuria. Discordant expression of glycosylphosphatidylinositol-linked proteins. J. Clin. Invest. 87:58-67.

30. Ueda, E., T. Kinoshita, T. Terasawa, Y. Yawata, K. Inoue, and T. Kitani. 
1990. Acetylcholinesterase and lymphocyte function-associated antigen 3 found on decay-accelerating factor-negative erythrocytes from some patients with paroxysmal nocturnal hemoglobinuria. Blood. 75:762-769.

31. Rock, K. L., E. T. H. Yeh, C. F. Gramm, S. I. Haber, H. Reiser, and B. Benacerraf. 1986. TAP, a novel T cell activating protein involved in the stimulation of MHC-restricted lymphocytes. J. Exp. Med. 163:315-333.

32. Davignon, D., E. Martz, T. Reynolds, K. Kurzinger, and T. A. Springer. 1981. Lymphocyte function associated antigen 1 (LFA-1): a surface antigen distinct from Lyt-2,3 that participates in T lymphocyte-mediated killing. Proc. Natl. Acad. Sci. USA. 78:4535-4539.

33. Leo, O., M. Foo, D. H. Sachs, L. E. Samelson, and J. A. Bluestone. 1987. Identification of a monoclonal antibody specific for a murine $\mathrm{T} 3$ polypeptide. Proc. Natl. Acad. Sci. USA. 84:1374-1378.

34. Beck, P. J., P. Orlean, C. Albright, P. W. Robbins, M. J. Gething, and J. F. Sambrook. 1990. The $S$. cervisiae DPM1 gene encoding dolichol-phosphatemannose synthase is able to complement a glycosylation-defective mammalian cell line. Mol. Cell. Biol. 10:4612-4622.
35. Yeh, E. T. H., H. Reiser, A. Bamezai, and K. Rock. 1988. TAP transcription and phosphatidylinositol linkage mutants are defective in activation through the T cell receptor. Cell. 52:665-674.

36. Singh, N., and A. M. Tartakoff. 1991. Two different mutants blocked in synthesis of Dolichol-phosphoryl mannose do not add glycophospholipid anchors to membrane proteins: quantitative correction of the phenotype of a $\mathrm{CHO}$ cell mutant with tunicamycin. Mol. Cell. Biol. 11:391-400.

37. Parekh, R. B., A. G. D. Tse, R. A. Dwek, A. F. Williams, and T. W Rademacher. 1987. Tissue-specific N-glycosylation, site-specific oligosaccharide patterns and lentil lectin recognition of rat Thy-1. EMBO (Eur. Mol. Biol. Or gan.) J. 6:1233-1244.

38. LeClair, K. P., R. G. E. Palfree, P. M. Flood, U. Hammerling, and A. Bothwell. 1986. Isolation of a murine Ly-6A cDNA reveals a new multigene family. EMBO (Eur. Mol. Biol. Organ.) J. 5:3227-3234.

39. Reiser, H., J. Coligan, E. Palmer, B. Benacerraf, and K. L. Rock. 1988. Cloning and expression of a cDNA for the T cell activating protein TAP. Proc. Natl. Acad. Sci. USA. 85:2255-2258. 